\title{
Investigation of vapor-phase silica deposition on MCM-41, using tetraalkoxysilanes
}

\author{
Karina Fodor, Johannes H. Bitter, Krijn P. de Jong* \\ Department of Inorganic Chemistry and Catalysis, Debye Institute, Utrecht University, P.O. Box 80083, 3508 TB Utrecht, \\ The Netherlands
}

Received 3 January 2002; received in revised form 17 June 2002; accepted 18 June 2002

\begin{abstract}
Chemical vapor deposition of silica, using tetraalkoxysilanes, on mesoporous templated silica, MCM-41, resulted in ordered silica with pores on the borderline of mesoporous $(2-50 \mathrm{~nm})$ and microporous materials $(<2 \mathrm{~nm})$. The resulting materials were characterized by nitrogen and argon physisorption, XRD, transmission electron microscopy, thermogravimetric analysis and infrared spectroscopy. By tuning the deposition conditions the pore size of MCM-41 $(\approx 3 \mathrm{~nm})$ was gradually decreased to $\approx 2 \mathrm{~nm}$.
\end{abstract}

(c) 2002 Elsevier Science Inc. All rights reserved.

Keywords: MCM-41; Vapor-phase silica deposition; Pore size tuning; Tetraalkoxysilanes; Template removal

\section{Introduction}

Chemical vapor (and liquid) deposition of alkoxy silanes (or alkylchloro silanes) on zeolites is used to improve shape selectivity by passivation of the external surface acidity (non-shape-selective sites) and by narrowing the pore mouth [1]. Tetraethoxy- and tetramethoxysilane molecules (TEOS and TMOS, respectively) are not expected to enter the channels of zeolites because they are too large for the relatively small pores of zeolites (critical diameter of TMOS is $\sim 0.9 \mathrm{~nm}$, that of TEOS is $\sim 1 \mathrm{~nm}$ ). Chemical vapor and liquid deposition of TEOS was investigated not only on

\footnotetext{
${ }^{*}$ Corresponding author. Fax: +31-30-251-1027.

E-mail address: k.p.dejong@chem.uu.nl (K.P. de Jong).
}

HZSM-5, but also on the much less acidic silicalite-1 (contains traces of aluminum), and on amorphous silica (not acidic) [2]. During chemical vapor deposition at low temperature $\left(50{ }^{\circ} \mathrm{C}\right)$ TEOS was only physically adsorbed on silica, because it could only decompose on acid sites. But at higher temperature $\left(400{ }^{\circ} \mathrm{C}\right)$ the silanol groups of silica were probably able to decompose TEOS since the formation of water and ethylene was observed. Thermal deposition of silica from TMOS was studied on the non-acidic silicalite-1, in a static vacuum system, in order to achieve shapeselective adsorption of paraffins [3]. The deposition rate increased substantially with increasing temperature, ranging from 240 to $500{ }^{\circ} \mathrm{C}$, resulting in an effective reduction of the pore mouth. The carbonaceous residues formed upon deposition were removed by oxidation/calcination. Zhao and coworkers [4] reported the vapor-phase silylation of 
ordered mesoporous silica, MCM-41, with TEOS to narrow selectively the pore mouth (from $\sim 3$ to $1.4 \mathrm{~nm}$ ) of MCM-41, after the template had been partially removed, allegedly from around the pore mouth, with AcOH/toluene extraction.

Presently, we are interested in the preparation of host materials suitable for immobilization of homogeneous catalysts. Mesoporous templated silicas [5] are promising applicants for this purpose. Homogeneous complexes can be entrapped in their pores if the size of the pore mouth is effectively decreased (unconstrained homogeneous catalysis). Furthermore, controlled decrease of the pore size of ordered mesoporous silicas could provide us with new ordered porous materials in the pore size range between zeolites $(<1.3 \mathrm{~nm})$ and mesoporous silicas $(>2.5 \mathrm{~nm})$.

In this work, we have investigated the deposition of TEOSs and TMOSs on MCM-41, which has a non-acidic character, in a vapor-phase flow system, the aim being to find a simple way to decrease to pore size of mesoporous silica $(\sim 3 \mathrm{~nm})$ towards the supermicroporous region $(1-2 \mathrm{~nm})$. By this method the pore size of MCM-41 $(\sim 3 \mathrm{~nm})$ was gradually decreased to $2 \mathrm{~nm}$, while the longrange hexagonal order of the pores was retained. Upon silica deposition the thickness of the pore walls increases, thus, improved stability, compared to the parent MCM-41, is expected. The resulting materials were comprehensively characterized with nitrogen and argon physisorption, XRD, thermogravimetric analysis and infrared spectroscopy.

\section{Experimental}

\subsection{Synthesis of $M C M-41$}

MCM-41 was prepared according to a slightly adapted literature procedure [6]. Tetraethylammonium hydroxide (TEAOH, Acros Organics, 20 wt.\% aqueous solution) and cetyltrimethylammonium bromide (CTABr, Acros Organics) were dissolved in water by stirring at $35^{\circ} \mathrm{C}$. The silica source, fumed silica (Aerosol 380 Degussa), was added to this solution under stirring in $2 \mathrm{~h}$, and the resulting gel was aged at room temperature for
$24 \mathrm{~h}$. The molar composition of the gel was: $1 \mathrm{SiO}_{2}: 0.19 \mathrm{TEAOH}: 0.27 \mathrm{CTABr}: 40 \mathrm{H}_{2} \mathrm{O}$. Then the gel was transferred into a teflon-lined stainlesssteel autoclave and heated at $150{ }^{\circ} \mathrm{C}$ for $48 \mathrm{~h}$. The solid product was filtered off and washed several times with water, dried in air at $120{ }^{\circ} \mathrm{C}$ and calcined at $550{ }^{\circ} \mathrm{C}$ for $6 \mathrm{~h}$.

\subsection{Silica deposition experiments}

MCM-41 $(\approx 0.1 \mathrm{~g}$, particle size $<0.1 \mathrm{~mm})$ was dried at $300{ }^{\circ} \mathrm{C}$ for $4 \mathrm{~h}$ in a helium flow in a reactor (packed bed, diameter $\approx 15 \mathrm{~mm}$ ), and then cooled down to the desired deposition temperature. Then a helium flow $\left(50 \mathrm{~cm}^{3} / \mathrm{min}\right)$ saturated with TEOS or TMOS (both from Acros Organics) vapor at room temperature was led through the sample at the deposition temperature for the given time, followed by a He flow $\left(50 \mathrm{~cm}^{3} / \mathrm{min}\right)$ saturated with water vapor at room temperature for the given time and at the given temperature. The resulting material was dried at $20-200{ }^{\circ} \mathrm{C}$ in a nitrogen flow for several hours.

Silica deposition was also carried out by treating the air-dried MCM-41 at the desired temperature for the given time with a nitrogen flow (60 $\mathrm{cm}^{3} / \mathrm{min}$ ) saturated at room temperature with both TEOS and water vapor, i.e. the saturator was filled with a mixture of TEOS and water. When TMOS was used, a He flow $\left(50 \mathrm{~cm}^{3} / \mathrm{min}\right)$ was splitted into two parallel flows. One flow was led through a saturator containing TMOS, while the other was led through a saturator containing water. The two flows were mixed before entering the reactor containing MCM-41. After deposition the material was dried as described above.

\subsection{Partial removal of the template from uncalcined MCM-41}

As-synthesized, i.e. non-calcined MCM-41, was stirred at room temperature for $20 \mathrm{~h}$ in ethanol (p.a., Merck) containing the given amount of concentrated $\mathrm{HCl}$ (37 wt.\%, Fisher Scientific). The resulting material was centrifuged and washed several times with ethanol, followed by drying at $80{ }^{\circ} \mathrm{C}$ in air for several hours. 


\subsection{Characterization}

Nitrogen and argon physisorption measurements were performed at $-196{ }^{\circ} \mathrm{C}$ with a Micrometrics ASAP 2400 set-up. Prior to analysis the samples were outgassed at $100-300{ }^{\circ} \mathrm{C}$ under vacuum. The surface area, pore volume and pore diameter of the samples were calculated using BET [7] and $\mathrm{BJH}$ [8] theory (from the desorption branch), respectively. $T$-plot analysis was used to check the micropore volume [9a].

Note: The specific pore volume and surface area data were not corrected by the weight increase occurred upon silica deposition because of technical difficulties with the exact measurement of the change in weight due to water adsorbed on the silica surface. The weight increase upon silica deposition was however substantial, up to $20 \mathrm{wt} . \%$, when silica deposition was carried out in the presence of water vapor.

Thermogravimetric analysis was performed on a Perkin Elmer TGS-2 analyzer in air atmosphere with a heating rate of $5{ }^{\circ} \mathrm{C} / \mathrm{min}$.

Powder XRD patterns were obtained with a Philips 1710 powder diffractometer, using $\mathrm{CuK} \alpha$ radiation.

Transmission electron microscopy (TEM) images were recorded on a Philips CM-200 electron microscope operated at $200 \mathrm{keV}$. The sample material was mounted on a carbon grid by drying a droplet of a suspension of the sample in ethanol on the grid.

Fourier transform infrared spectra were recorded on a Perkin Elmer Spectrum One spectrometer equipped with a MIR-TGS detector. The dried silica sample was pressed into a self-supporting waffer with $0.5 \mathrm{~cm}$ diameter. The spectra were measured in the transmission mode.

\section{Results and discussion}

\subsection{Silica deposition on calcined MCM-41 using tetraalkoxysilanes}

MCM-41 was treated, after drying (in a He flow at $300{ }^{\circ} \mathrm{C}$ for $4 \mathrm{~h}$ ), at the given temperature with a He flow saturated with either TEOS or TMOS vapor and, subsequently, with a He flow saturated with water vapor (=1 silica deposition cycle), as described in the experimental part. During this procedure TEOS or TMOS molecules are adsorbed on the surface and react with the surface silanol groups of MCM-41, followed by hydrolysis of the surface alkoxy species to generate more surface silanol groups during treatment with water vapor.

Applying TEOS, one deposition cycle at $200{ }^{\circ} \mathrm{C}$ results in about $0.3 \mathrm{~nm}$ decrease in the pore diameter (Fig. 1). The decrease in both the specific pore volume and the surface area is in accordance with what is expected from geometrical considerations assuming cylindrical pores. This indicates that silica deposition on MCM-41 at $200{ }^{\circ} \mathrm{C}$ using TEOS proceeds rather uniformly throughout the pores. However, as shown in Fig. 1, the pore size distribution of the modified material is considerably broader, and the mesoporous step is not as sharp as in the case of the parent MCM-41, especially after the second silica deposition cycle.

Upon the first silica deposition cycle at $200{ }^{\circ} \mathrm{C}$ with TMOS, which is more reactive in silylation reactions than TEOS, the pore diameter of

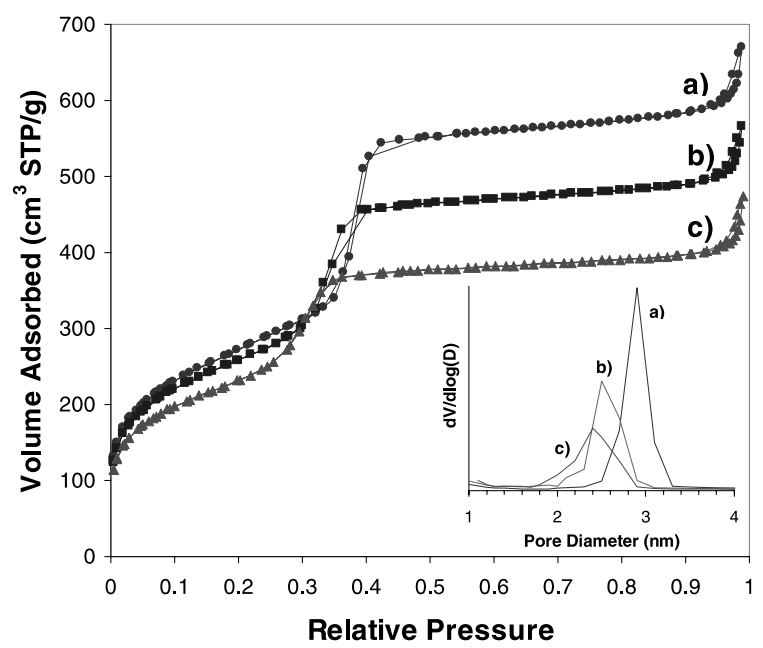

Fig. 1. $\mathrm{N}_{2}$ physisorption isotherms and pore size distributions of the parent MCM-41 (a), and MCM-41 after one silica deposition cycle (b), and after two silica deposition cycles (c), at $200{ }^{\circ} \mathrm{C}$ using TEOS. One silica deposition cycle: He $\left(50 \mathrm{~cm}^{3} /\right.$ min) saturated with TEOS at room temperature for $16 \mathrm{~h}$, followed by $\mathrm{He}\left(50 \mathrm{~cm}^{3} / \mathrm{min}\right)$ saturated with water at room temperature for $7 \mathrm{~h}$. 
Table 1

Textural properties of MCM-41 before and after silica deposition using TMOS at $200{ }^{\circ} \mathrm{C}$

\begin{tabular}{lcll}
\hline & BET $\left(\mathrm{m}_{2} / \mathrm{g}\right)$ & $V_{\text {pore }}\left(\mathrm{cm}^{3} / \mathrm{g}\right)$ & $\begin{array}{l}d_{\text {pore }}(\mathrm{BJH}) \\
(\mathrm{nm})\end{array}$ \\
\hline $\begin{array}{l}\text { MCM-41 } \\
\begin{array}{l}\text { After the 1st } \\
\text { deposition cycle }\end{array}\end{array}$ & 854 & 0.99 & 2.8 \\
$\begin{array}{l}\text { After the 2nd } \\
\text { deposition cycle }\end{array}$ & 814 & 0.77 & 2.3 \\
$\begin{array}{l}\text { After the 3rd } \\
\text { deposition cycle }\end{array}$ & 783 & 0.70 & 2.3 \\
\hline
\end{tabular}

One silica deposition cycle: $\mathrm{He}\left(50 \mathrm{~cm}^{3} / \mathrm{min}\right)$ saturated with TMOS at room temperature for $5 \mathrm{~h}$ followed by $\mathrm{He}\left(50 \mathrm{~cm}^{3} /\right.$ min) saturated with water at room temperature for $16 \mathrm{~h}$.

${ }^{\text {a }}$ Prior to the $3 \mathrm{rd}$ silica deposition cycle, the material was calcined in air at $350{ }^{\circ} \mathrm{C}$ for $4 \mathrm{~h}$.

MCM-41 decreased with around $0.5 \mathrm{~nm}$ (Table 1). Interestingly, upon the second deposition cycle neither the pore size nor the specific pore volume or surface area changed considerably, indicating that hardly any more silica was deposited. Silica deposition on MCM-41 using TMOS was carried out not only at $200{ }^{\circ} \mathrm{C}$, but also at lower temperatures, viz. 130 and $100{ }^{\circ} \mathrm{C}$. Here, again the pore diameter decreased with about $0.5 \mathrm{~nm}$ upon the first deposition cycle, but no further change in the structural properties occurred during the second or third deposition cycle.

In order to find the reason why silica deposition on MCM-41 stops, even at $200{ }^{\circ} \mathrm{C}$, when the pore diameter reaches $2.2-2.3 \mathrm{~nm}$, the samples on which silica was deposited at $200{ }^{\circ} \mathrm{C}$ using TEOS or TMOS were studied with FTIR. Performing silica deposition with TMOS or TEOS at $200{ }^{\circ} \mathrm{C}$ results in a surface mostly covered with silanol groups. On the FTIR spectra recorded at room temperature (not shown), a sharp peak at $3740 \mathrm{~cm}^{-1}$ corresponds to the free silanol groups; a broad band centered at around $3700 \mathrm{~cm}^{-1}$ and a very broad band around $3550 \mathrm{~cm}^{-1}$ are assigned to single silanol groups derived from geminal silanol groups upon silylation [10] and to silanol groups in hydrogen-bonding, respectively; the latter is disturbed by some physically adsorbed water, the intensity of which decreased when the sample was heated. However, the appearance of four peaks at around $3000-2800 \mathrm{~cm}^{-1}$ indicates that some organic residues ( $\sim 4 \mathrm{wt} . \%$ from TGA in the case of the sample treated with TMOS) are present as well. To remove the carbonaceous residue the sample modified with silica deposition at $200{ }^{\circ} \mathrm{C}$ using TMOS was calcined at $350{ }^{\circ} \mathrm{C}$ in air. Upon silica deposition on the calcined sample, the capillary condensation step of nitrogen shifted only slightly towards lower relative pressures, and the pore size decreased from 2.3 to $2.1 \mathrm{~nm}$ without considerable change in the specific pore volume or surface area (Table 1). Based on these observations, further deposition leading to smaller pore size seems to be inhibited rather by pore-blocking than by inactivation of the silica surface. Nevertheless, it was rather unexpected that silica deposition terminates at a pore diameter of $\sim 2.1 \mathrm{~nm}$, considering that the size of the TMOS molecule is around $0.9 \mathrm{~nm}$. It is important to note here that the absolute figures for the pore diameters of this size have to be treated with caution; in general, the $\mathrm{BJH}$ method underestimates the pore diameter of mesoporous materials [11].

On the basis of XRD patterns (not shown) the long-range hexagonal ordering of the pores was completely kept upon silica deposition, as all the four diffraction peaks characteristic of the parent MCM-41 were also present in the diffractogram of the modified materials. This was further confirmed by TEM studies.

\subsection{Silica deposition on calcined MCM-41 using a mixture of tetraalkoxysilane and water vapor}

In order to increase the silica deposition rate, and, thus, the amount of silica deposited, in the following experiments MCM-41 was treated at different temperatures with TEOS (or TMOS) vapor in the presence of water vapor, since water physisorbed on the silica surface is known to catalyze the reaction of alkoxy silanes with the surface silanol groups. We have to note that under the silica deposition conditions used no silica formation was observed in the absence of MCM-41.

Based on the observation that the weight increase (data not shown) upon deposition in the presence of water is considerably greater than that in the absence of water, it can be concluded that a considerably larger amount of silica can be 
Table 2

Textural properties of MCM-41 before and after silica deposition with TEOS $+\mathrm{H}_{2} \mathrm{O}$ for $3 \mathrm{~h}$ at different temperatures

\begin{tabular}{lcll}
\hline $\begin{array}{l}\text { Deposition } \\
\text { temperature }\left({ }^{\circ} \mathrm{C}\right)\end{array}$ & BET $\left(\mathrm{m}^{2} / \mathrm{g}\right)$ & $\begin{array}{l}V_{\text {pore }} \\
\left(\mathrm{cm}^{3} / \mathrm{g}\right)\end{array}$ & $\begin{array}{l}d_{\text {pore }}(\mathrm{BJH}) \\
(\mathrm{nm})\end{array}$ \\
\hline None & 1081 & 1.03 & 2.8 \\
130 & 913 & 0.86 & 2.6 \\
300 & 876 & 0.70 & 2.3 \\
400 & 822 & 0.59 & 2.1 \\
\hline
\end{tabular}

deposited in the presence than in the absence of water. The amount of silica deposited increases with increasing deposition temperature or time. As a result, the pore size of MCM-41 can be gradually decreased by increasing the deposition temperature or time, as can be seen in Tables 2-4.

The pore size distribution becomes significantly broader upon modification, especially at higher temperatures or longer deposition times. Silica deposition with a mixture of TEOS or TMOS and water vapor occurs everywhere inside the pores (as well as on the external surface) but, probably, much less uniformly than in the case of silylation with TEOS or TMOS vapor first followed by hydrolysis with water vapor. If we take into consideration that the specific pore volume and surface area would be considerably higher (up to $20 \%$ ) if we correct these specific data by the weight increase upon deposition, it seems that silica deposition in the presence of water vapor occurs to a greater extent on the external surface area and near the pore mouth than inside the pores.

As shown in Tables 3 and 4, the decrease in pore size upon silica deposition on MCM-41 either with TEOS $+\mathrm{H}_{2} \mathrm{O}$ or with TMOS $+\mathrm{H}_{2} \mathrm{O}$, even at 200 or $300{ }^{\circ} \mathrm{C}$, ceases at around $2.1 \mathrm{~nm}$ pore diameter.

Silica deposition with alkoxy silanes in the presence of water is incomplete below $200{ }^{\circ} \mathrm{C}$, on
Table 4

Textural properties of MCM-41 before and after silica deposition with TMOS $+\mathrm{H}_{2} \mathrm{O}$ at $200{ }^{\circ} \mathrm{C}$ for different times

\begin{tabular}{lcll}
\hline $\begin{array}{l}\text { Deposition } \\
\text { time }(\mathrm{h})\end{array}$ & BET $\left(\mathrm{m}^{2} / \mathrm{g}\right)$ & $\begin{array}{l}V_{\text {pore }} \\
\left(\mathrm{cm}^{3} / \mathrm{g}\right)\end{array}$ & $\begin{array}{l}d_{\text {pore }}(\mathrm{BJH}) \\
(\mathrm{nm})\end{array}$ \\
\hline None & 1056 & 0.99 & 2.8 \\
3 & 865 & 0.76 & 2.4 \\
6 & 817 & 0.71 & 2.3 \\
\hline
\end{tabular}

the basis of thermogravimetric analysis and infrared spectroscopy, i.e. the surface ethoxy or methoxy groups are only partly hydrolyzed to silanol groups. The surface of MCM-41 on which silica was deposited from TEOS and water vapor at $100{ }^{\circ} \mathrm{C}$ became considerably more hydrophobic compared to the parent sample due to the presence of the ethoxy groups and, most likely, physically adsorbed TEOS. Calcination of this sample at 300 ${ }^{\circ} \mathrm{C}$ in air brought about additional hydrolysis/ condensation on the modified silica surface and, as a result, the pore size decreased from 2.4 to $2.1 \mathrm{~nm}$.

No significant change was visible in the TEM images of MCM-41 upon silica deposition in the presence of water (Fig. 2). Formation of amorphous silica on the external surface of MCM-41 was not observed. Furthermore, XRD patterns of the modified silicas contained three diffraction peaks indicating that the long-range hexagonal pore order of the parent MCM-41 was retained (Fig. 3). As expected the interplanar spacing $\left(d_{100}\right)$ did not change significantly upon modification.

\subsection{Silica deposition on non-calcined MCM-41} from which the template has partially been removed by extraction

In order to further investigate silica deposition on MCM-41, we followed the method reported by Zhao and coworkers [4]. The authors stated that

Table 3

Textural properties of MCM-41 before and after silica deposition with TEOS $+\mathrm{H}_{2} \mathrm{O}$ at $200{ }^{\circ} \mathrm{C}$ and at $300{ }^{\circ} \mathrm{C}$ for different times

\begin{tabular}{|c|c|c|c|c|c|c|}
\hline \multirow[t]{2}{*}{ Deposition time (h) } & \multicolumn{3}{|l|}{$200^{\circ} \mathrm{C}$} & \multicolumn{3}{|l|}{$300^{\circ} \mathrm{C}$} \\
\hline & $\overline{\operatorname{BET}\left(\mathrm{m}^{2} / \mathrm{g}\right)}$ & $V_{\text {pore }}\left(\mathrm{cm}^{3} / \mathrm{g}\right)$ & $d_{\text {pore }}(\mathrm{BJH})(\mathrm{nm})$ & $\operatorname{BET}\left(\mathrm{m}^{2} / \mathrm{g}\right)$ & $V_{\text {pore }}\left(\mathrm{cm}^{3} / \mathrm{g}\right)$ & $d_{\text {pore }}(\mathrm{BJH})(\mathrm{nm})$ \\
\hline None & 1076 & 1.05 & 2.8 & 1081 & 1.03 & 2.8 \\
\hline 3 & 961 & 0.86 & 2.5 & 876 & 0.70 & 2.3 \\
\hline 16 & 792 & 0.68 & 2.2 & 743 & 0.57 & 2.1 \\
\hline 36 & 760 & 0.60 & 2.2 & & & \\
\hline
\end{tabular}



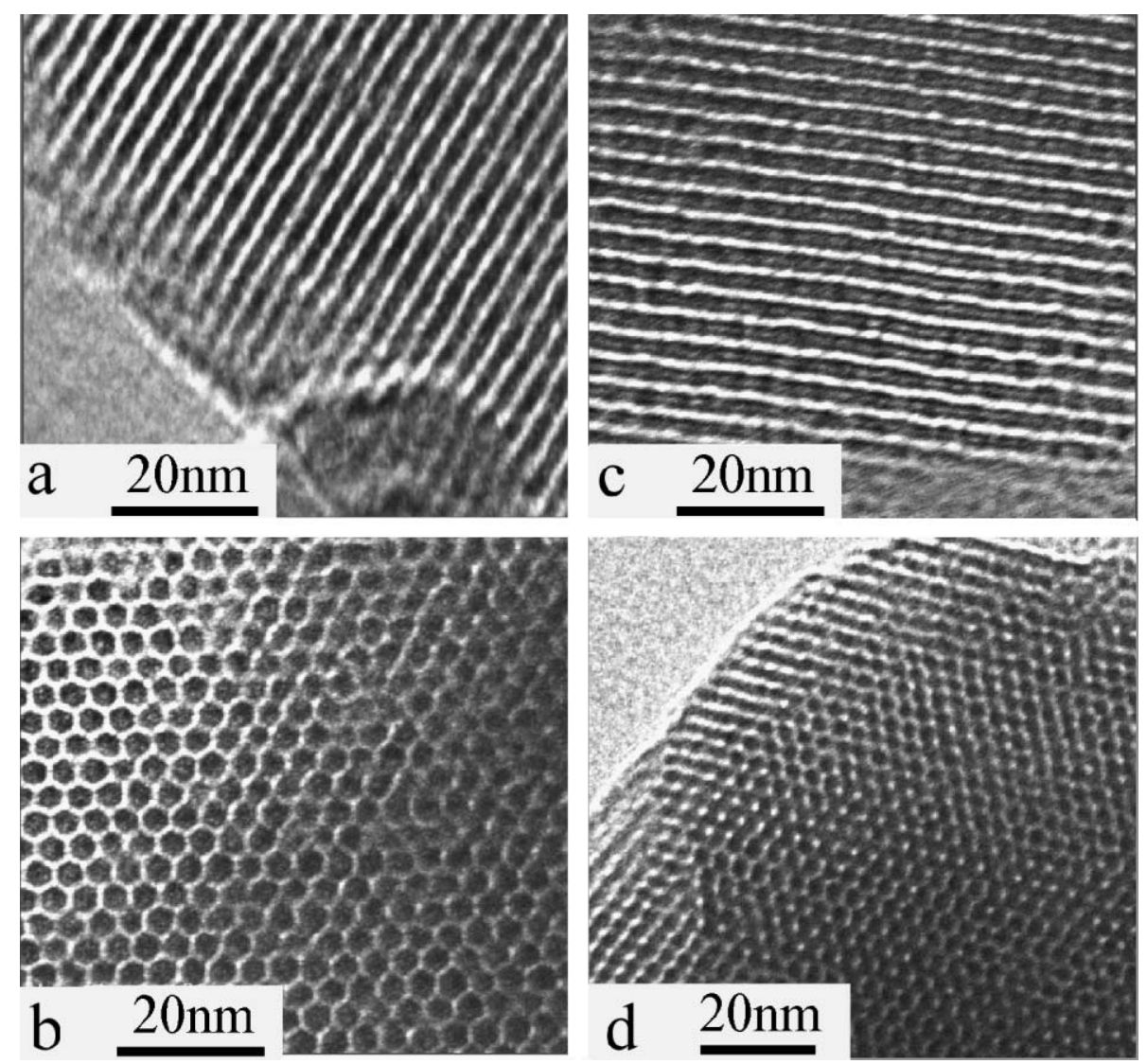

Fig. 2. TEM images of the parent MCM-41 (a,b) and MCM-41 after silica deposition with TEOS $+\mathrm{H}_{2} \mathrm{O}$ for $3 \mathrm{~h}$ at $300{ }^{\circ} \mathrm{C}(\mathrm{c}, \mathrm{d})$.

by this method the size of the pore mouth of MCM-41 could be decreased without significant loss in the pore volume and surface area. They described the partial removal of the template, cetyltrimethylammonium chloride, from uncalcined MCM-41 by stirring it with around 0.2 equivalent $\mathrm{AcOH}$ (with respect to the template content of the uncalcined MCM-41) in toluene. The resulting material was treated with TEOS vapor followed by treatment with water vapor at $200{ }^{\circ} \mathrm{C}$, followed by calcination to remove the rest of the surfactant. In our hands, however, no template was removed by the above described extraction method, probably due to the low solubility of the surfactant in toluene. In our approach we used $\mathrm{HCl}$ in ethanolic solution at room temperature for template extraction. As can be seen from Fig. 4, the amount of template removed by extraction from uncalcined
MCM-41 can be gradually increased with increasing $\mathrm{HCl} /$ surfactant molar ratio. At room temperature around $80 \%$ of the surfactant can be removed by extraction with excess $\mathrm{HCl}$ (30-fold). Note the good reproducibility of the extraction, which was tested by using 0.2 equivalent $\mathrm{HCl}$.

Unlike under reflux conditions (often used in literature [12]), performing template extraction with $\mathrm{HCl}$ in ethanol at room temperature reaction of the silanol groups with ethanol does not take place, and thus, the silica surface remains active for further reaction with alkoxy silanes.

Uncalcined MCM-41 was extracted with 0.2 equivalent $\mathrm{HCl}$ (with respect to the amount of surfactant in MCM-41) in EtOH at room temperature, followed by treatment with TEOS vapor and, afterwards, with water vapor, at 100,130 or $200{ }^{\circ} \mathrm{C}$. Finally, the sample was calcined at $550{ }^{\circ} \mathrm{C}$ 


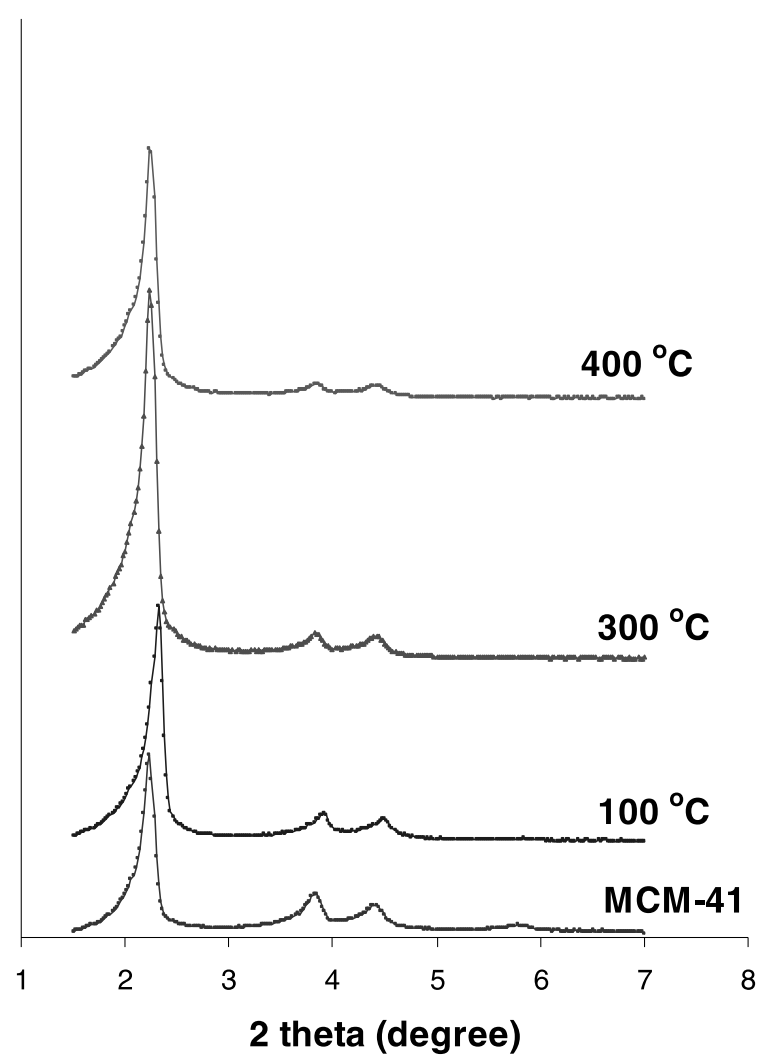

Fig. 3. Powder XRD patterns of the parent MCM-41, and after silica deposition with TEOS $+\mathrm{H}_{2} \mathrm{O}$ for $3 \mathrm{~h}$ at different temperatures.

to remove the rest of the surfactant. Pore size distributions, calculated from nitrogen physisorption measurements, are shown on Fig. 5.

On the basis of the weight decrease upon calcination of MCM-41 extracted with 0.2 equivalent $\mathrm{HCl}$ and then modified with silica deposition at $200{ }^{\circ} \mathrm{C}$ (for $16 \mathrm{~h}$ ), a large amount of the surfactant decomposes already during silica deposition. As a result, it cannot prevent anymore TEOS from going inside the pores, and thus, silica deposition gives roughly the same result as silica deposition on the calcined MCM-41 (see Table 5). Decomposition of the template, in accordance with TGA (Fig. 4), starts already around $130{ }^{\circ} \mathrm{C}$, and up to $200{ }^{\circ} \mathrm{C}$ a considerable amount of the template is removed, especially at prolonged deposition times. This is in agreement with the findings of Kleitz et al. [13] that below $250{ }^{\circ} \mathrm{C}$ around $50 \%$ of the

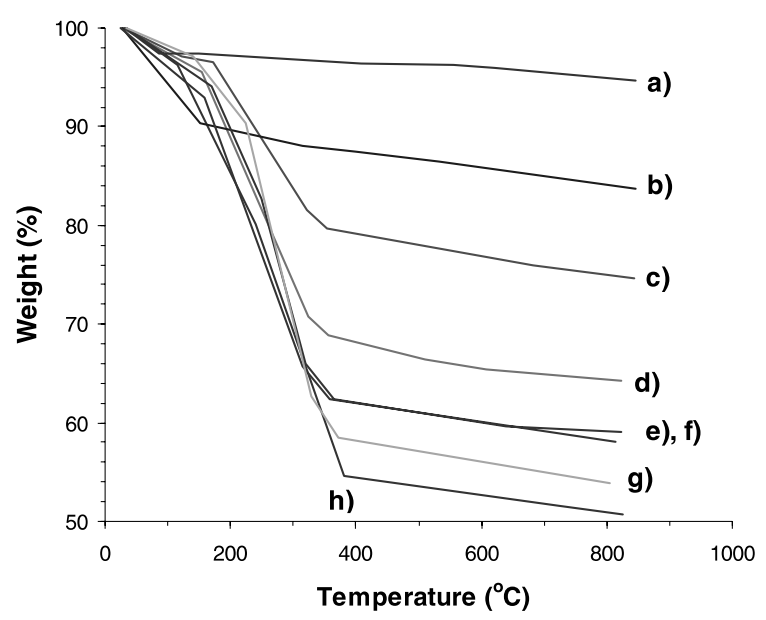

Fig. 4. TG curves of calcined MCM-41 (a), and of uncalcined MCM-41 (h) after treatment with different amounts of $\mathrm{HCl}$ in ethanol: large excess (b), 0.5 (c), 0.25 (d), 0.2 (e,f), equivalent with respect to the surfactant content of the uncalcined MCM41 , and 0.2 equivalent $\mathrm{HCl}$ in water $(\mathrm{g})$, at room temperature.

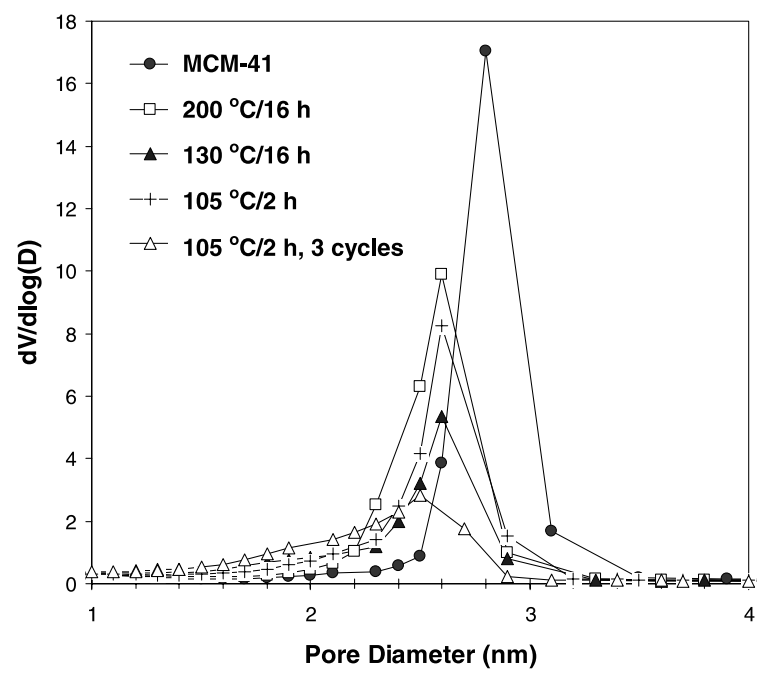

Fig. 5. Pore size distribution curves, calculated from $\mathrm{N}_{2}$ physisorption measurements, of the parent MCM-41, and of MCM41 containing $\sim 80 \%$ of surfactant subjected to silica deposition at different temperatures followed by calcination. One silica deposition cycle: $\mathrm{He}\left(50 \mathrm{~cm}^{3} / \mathrm{min}\right)$ saturated with TEOS at room temperature for 16 or $2 \mathrm{~h}$, followed by $\mathrm{He}\left(50 \mathrm{~cm}^{3} / \mathrm{min}\right)$ saturated with water at room temperature for $7 \mathrm{~h}$.

template is removed by evaporation of the alkene resulting from Hofmann elimination. Similarly, carrying out silica deposition at $130{ }^{\circ} \mathrm{C}$ (for $16 \mathrm{~h}$ ) leads to some decomposition of the template. 
Table 5

Textural properties (from $\mathrm{N}_{2}$ physisorption measurements) of MCM-41 containing around $80 \%$ of surfactant after silica deposition at different temperatures and for different times, followed by calcination

\begin{tabular}{llrll}
\hline $\begin{array}{l}\text { Deposition } \\
\text { temperature } \\
\left({ }^{\circ} \mathrm{C}\right)\end{array}$ & $\begin{array}{l}\text { Deposition } \\
\text { time }(\mathrm{h})^{\mathrm{a}}\end{array}$ & $\begin{array}{l}\mathrm{BET} \\
\left(\mathrm{m}^{2} / \mathrm{g}\right)\end{array}$ & $\begin{array}{l}V_{\text {pore }} \\
\left(\mathrm{cm}^{3} / \mathrm{g}\right)\end{array}$ & $\begin{array}{l}d_{\text {pore }}(\mathrm{BJH}) \\
(\mathrm{nm})\end{array}$ \\
\hline None & none & 1076 & 1.05 & 2.8 \\
200 & 16 & 932 & 0.76 & 2.6 \\
$200^{\mathrm{b}}$ & 16 & 879 & 0.79 & 2.6 \\
130 & 16 & 851 & 0.66 & 2.6 \\
105 & 2 & 975 & 0.79 & 2.6 \\
105 & $2(3$ cycles $)$ & 830 & 0.57 & $\sim 2.5$ \\
\hline
\end{tabular}

${ }^{\mathrm{a}}$ One silica deposition cycle: $\mathrm{He}\left(50 \mathrm{~cm}^{3} / \mathrm{min}\right)$ saturated with TEOS at room temperature for 16 or $2 \mathrm{~h}$, followed by $\mathrm{He}(50$ $\mathrm{cm}^{3} / \mathrm{min}$ ) saturated with water at room temperature for $7 \mathrm{~h}$.

${ }^{\mathrm{b}}$ Calcination to remove all the template before silica deposition.

Although no template decomposition was observed when silica deposition was carried out at $105{ }^{\circ} \mathrm{C}$, the decrease in specific pore volume was much more than what was expected from the decrease in the pore size if only the pore mouth is affected. Since the surfactant blocked the inside of the pores, this decrease in pore volume can be attributed to intensive pore-blocking upon silica deposition, probably due to the large amount of TEOS physisorbed at such a low temperature. Repeating silica deposition three times at $105{ }^{\circ} \mathrm{C}$ resulted in a very broad pore size distribution, the maximum of which was still at $2.5 \mathrm{~nm}$, but the amount of pores smaller than $2.5 \mathrm{~nm}$ increased considerably (Fig. 5, Table 5). However, by the $t$ plot analysis no micropores were detected.

No change in the pore shape of MCM-41 was visible by TEM since, due to focus problem, it is difficult to analyze the pore size and wall thickness exactly. Again, no formation of amorphous silica on the external surface of MCM-41 was observed.

Argon physisorption isotherms (at $77 \mathrm{~K}$ ) of the parent MCM-41, of calcined MCM-41 subjected to silica deposition at $200{ }^{\circ} \mathrm{C}$, and of MCM-41 containing around $80 \%$ of surfactant subjected to silica deposition at $105^{\circ} \mathrm{C}$ followed by calcination were also recorded in order to test whether an adsorption-desorption hysteresis loop was visible, and, it so, whether there was a change in its shape (Fig. 6). In contrast to $N_{2}$ physisorption, Ar physisorption

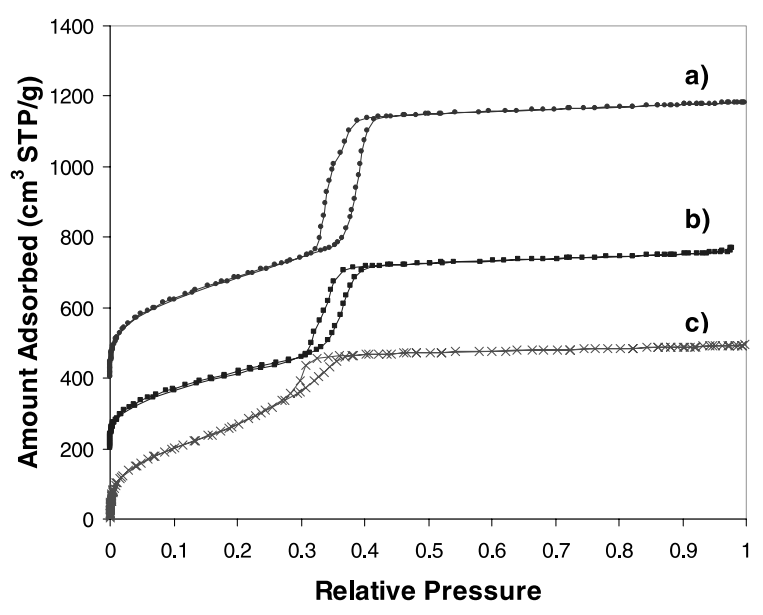

Fig. 6. Ar physisorption isotherms of the parent MCM-41 (a), of the calcined MCM-41 after silica deposition at $200{ }^{\circ} \mathrm{C}$ (b) and of MCM-41 containing $\sim 80 \%$ of surfactant subjected to silica deposition at $105{ }^{\circ} \mathrm{C}$, followed by calcination (c) (the former two have been offset ( $y$ axis) by 200).

isotherms of all the three samples showed hysteresis, in agreement with literature $[11,14,15]$. The hysteresis loops of both the parent MCM-41 and the one silylated at $200{ }^{\circ} \mathrm{C}$ after calcination had a similar shape (type $\mathrm{H} 1$ [9b]), characteristic of cylindrical pores. The hysteresis loop had a different shape, somewhat triangular (type $\mathrm{H} 2$ [9b]), with the sample on which silica was deposited while the pores were partly filled with template. This might be the result of a change in the pore shape, i.e. ink bottle-like instead of cylindrical.

\section{Conclusion}

By silica deposition using TEOS or TMOS in a vapor-phase flow system, at relatively low temperatures, the pore size of MCM-41 can be decreased gradually from the mesopore towards micropore region. However, it seems that, under the conditions used so far, a pore diameter smaller than $2 \mathrm{~nm}$ is difficult to achieve, most likely due to pore-blocking. Upon silica deposition the hexagonal ordering of the pores is retained. The resulting material has pore walls covered with silanol groups that are ready for further modification, i.e. grafting or tethering of active components. 


\section{Acknowledgements}

Financial support is gratefully acknowledged to NRSC-Catalysis (the Netherlands). Fred Broersma, Sandra Kemp, Ad Mens, John Raaymakers $(\dagger)$, Marjan Versluijs are thanked for characterization. The authors are indebted to the referees for their useful remarks.

\section{References}

[1] M. Niwa, S. Kato, T. Hattori, Y. Murakami, J. Chem. Soc., Faraday Trans. 1 (80) (1984) 3135;

M. Niwa, M. Kato, T. Hattori, Y. Murakami, J. Phys. Chem. 90 (1986) 6233;

T. Hibino, M. Niwa, Y. Murakami, J. Catal. 128 (1991) 551 ;

J.H. Kim, A. Ishida, M. Okajima, M. Niwa, J. Catal. 161 (1996) 387;

M. Niwa, K. Yamazaki, Y. Murakami, Ind. Eng. Chem. Res. 33 (1994) 371.

[2] R.W. Weber, K.P. Möller, M. Unger, C.T. O'Connor, Micropor. Mesopor. Mater. 23 (1998) 179.

[3] H.A. Begum, N. Katada, M. Niwa, Micropor. Mesopor. Mater. 46 (2001) 13.
[4] X. Hu, S. Qiao, X. Song Zhao, G.Q. Lu, Ind. Eng. Chem. Res. 40 (2001) 862;

X. Song Zhao, G.Q. Lu, X. Hu, Chem. Commun. (1999) 1391.

[5] J.S. Beck, J.C. Vartuli, W.J. Roth, M.E. Leonowicz, C.T. Kresge, K.D. Schmitt, C.T.-W. Chu, D.H. Olson, E.W. Sheppard, S.B. McCullen, J.B. Higgins, J.L. Schlenker, J. Am. Chem. Soc. 114 (1992) 10834.

[6] C.-F. Cheng, D.H. Park, J. Klinowski, J. Chem. Soc., Faraday Trans. 93 (1) (1997) 193.

[7] S. Brunauer, P.H. Emmet, E. Teller, J. Am. Chem. Soc. 60 (1938) 309.

[8] E.P. Barrett, L.G. Joyner, P.P. Halenda, J. Am. Chem. Soc. 73 (1951) 373.

[9] (a) S.J. Gregg, K.S.W. Sing, Adsorption, in: Surface Area and Porosity, second ed., Academic Press, New York, 1982, p. 80;

(b) K.S.W. Sing, Pure \& Appl. Chem. 54 (1982) 2201.

[10] X.S. Zhao, G.Q. Lu, A.K. Whittaker, G.J. Millar, H.Y. Zhu, J. Phys. Chem. B. 101 (1997) 6525.

[11] M. Kruk, M. Jaroniec, Chem. Mater. 13 (2001) 3169.

[12] K. Cassiers, P. Van Der Voort, E.F. Vansant, Chem. Commun. (2000) 2489.

[13] F. Kleitz, W. Schmidt, F. Schüth, Micropor. Mesopor. Mater. $44-45$ (2001) 95.

[14] M. Kruk, M. Jaroniec, S. Guan, S. Inagaki, J. Phys. Chem. B. 105 (2001) 681.

[15] A.V. Neimark, P.I. Ravikovitch, M. Grun, F. Schüth, K.K. Unger, J. Colloid Interface Sci. 207 (1998) 159. 